\title{
Cirsoid aneurysm of scalp: demonstration on CT angiography (CTA)
}

Vandana Goel, ${ }^{1}$ Amit Kumar Verma, ${ }^{1,2}$ Satbir Singh, ${ }^{1}$ Sunil Kumar Puri ${ }^{1}$

${ }^{1}$ Department of Radiology, GB Pant Hospital, New Delhi, India

${ }^{2}$ Department of Radiology, King George Medical University, Lucknow, India

\section{Correspondence to}

Dr Sunil Kumar Puri, skpurigbph@yahoo.co.in

\section{DESCRIPTION}

A 16-year-old girl presented with a progressively increasing pulsatile subcutaneous scalp swelling with linear tortuous structures in the frontoparietal region. A loud bruit was heard on auscultation. General examination and haematological investigations were unremarkable. In suspicion of arteriovenous malformation a CT angiography (CTA) was performed which showed a large vascular mass formed of bunch of dilated and tortuous vessels in the scalp. Feeders from bilateral superficial temporal arteries were identified with venous drainage by superficial scalp veins

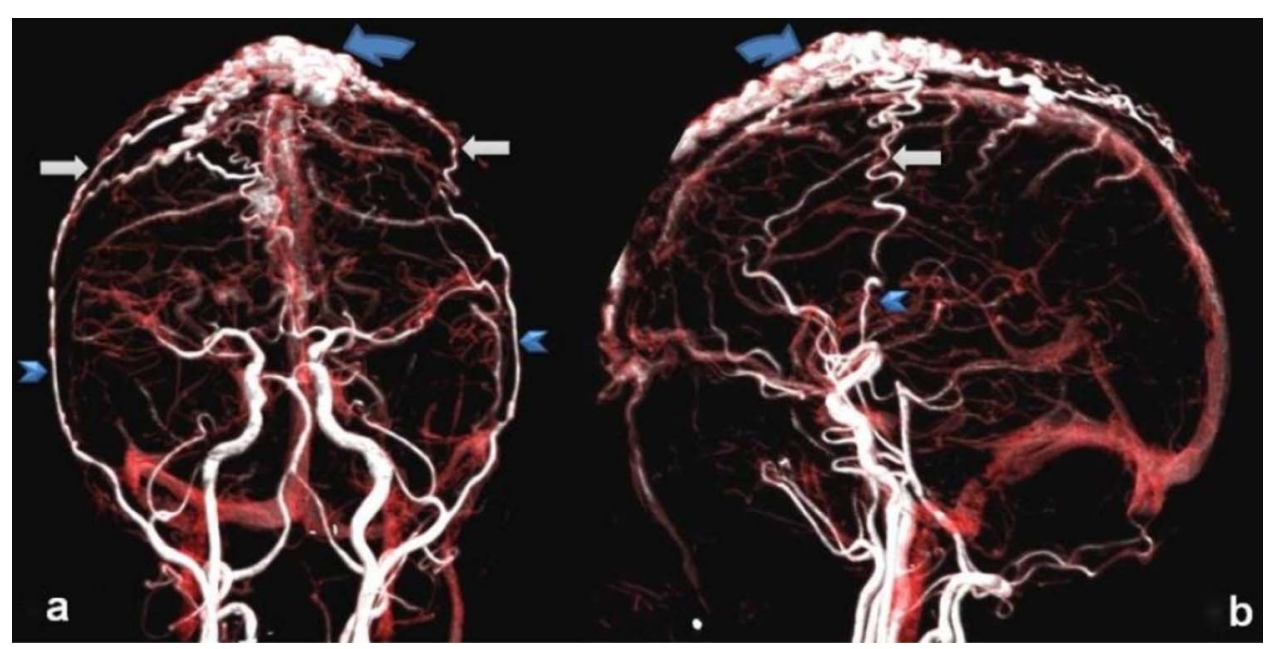

Figure 1 (A and B) CT angiography volume rendered images in anteroposterior and lateral oblique views show a vascular mass (curved arrow) composed of a bunch of tortuous vessels in the scalp subcutaneous plane of frontoparietal region. The arterial feeders (arrow) from both superficial temporal arteries (arrow head) are supplying the lesion.

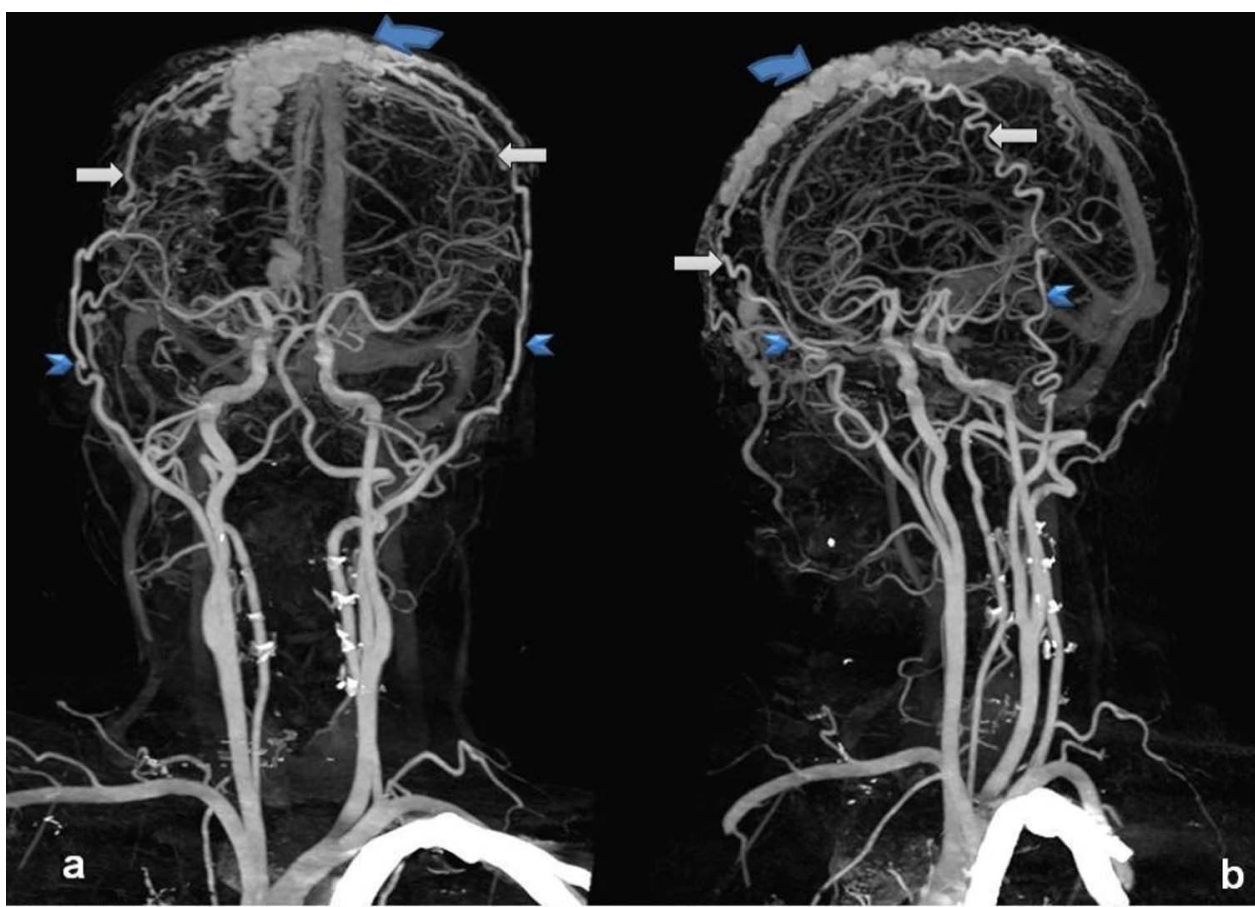

Figure 2 (A and B) CT angiography maximum intensity projection images of neck vessels and brain showing a vascular malformation (curved arrow) in a scalp subcutaneous plane with arterial feeders (arrow) from bilateral superficial temporal arteries (arrow head). Neck vessels including bilateral carotid and vertebral arteries are unremarkable. 
Figure 3 ( $A$ and $B$ ) Axial maximum intensity projection images of superior part of the head showing subcutaneous vascular scalp lesion in the superior frontal region (arrow).

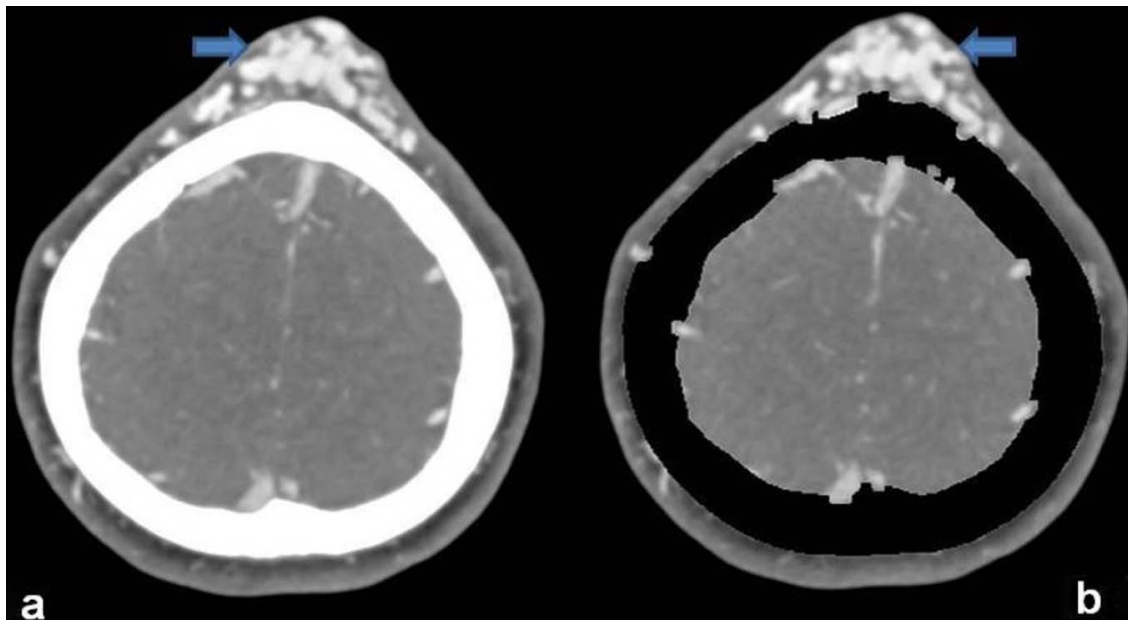

(figures 1-3). On the basis of clinical and CTA findings a final diagnosis of cirsoid aneurysm was made. The patient underwent open surgery with ligation of the feeders and excision of the arteriovenous fistula (AVF).

Cirsoid aneurysm of the scalp is an AVF having abnormal connections between the feeding arteries and draining veins, without an intervening capillary bed. ${ }^{1}$ They are usually congenital in aetiology, however, traumatic fistulas have also been described. $^{2}$ In the majority $(\sim 90 \%)$ of the patients, the superfi-

\section{Learning points}

- Cirsoid aneurysm is an arteriovenous fistula (AVF).

- Majority of the scalp AVF are supplied by either one or both the superficial temporal arteries.

- A CT angiography can play a pivotal role in planning the treatment by tracing the feeder vessels and giving the relation of lesion with adjacent structures.

- Catheter angiography is still a gold standard technique with therapeutic benefits. cial temporal artery is the main supply to the fistula with one dominant feeding artery in $71 \%$ of patients. ${ }^{3}$ Patients usually present with progressively increasing compressible, pulsatile scalp swelling with some facial disfigurement and a loud bruit on auscultation.

Imaging plays an important role in the diagnosis. CTA gives the actual location and extension of the lesion along with its relation to adjacent cranial structures. Over all CTA traces arterial feeders and venous drainage accurately and acts as a pivot in planning the appropriate treatment. Catheter angiography is still the gold standard with its therapeutic benefits in endovascular treatment.

Competing interests None.

Patient consent Obtained.

Provenance and peer review Not commissioned; externally peer reviewed.

\section{REFERENCES}

1 Rappaport I, Yim D. Congenital arteriovenous fistulas of the head and neck. Arch Otolaryngol 1973;97:350-3

2 Muthukumar N, Rajagopal V, Manoharan A, et al. Surgical management of cirsoid aneurysms. Acta Neurochir (Wien) 2002;144:349-56

3 Gurkanlar D, Gonul M, Solmaz I, et al. Cirsoid aneurysms of the scalp. Neurosurg Rev 2006;29:208-12

Copyright 2013 BMJ Publishing Group. All rights reserved. For permission to reuse any of this content visit

http://group.bmj.com/group/rights-licensing/permissions.

BMJ Case Report Fellows may re-use this article for personal use and teaching without any further permission.

Become a Fellow of BMJ Case Reports today and you can:

- Submit as many cases as you like

- Enjoy fast sympathetic peer review and rapid publication of accepted articles

- Access all the published articles

- Re-use any of the published material for personal use and teaching without further permission

For information on Institutional Fellowships contact consortiasales@bmjgroup.com

Visit casereports.bmj.com for more articles like this and to become a Fellow 